
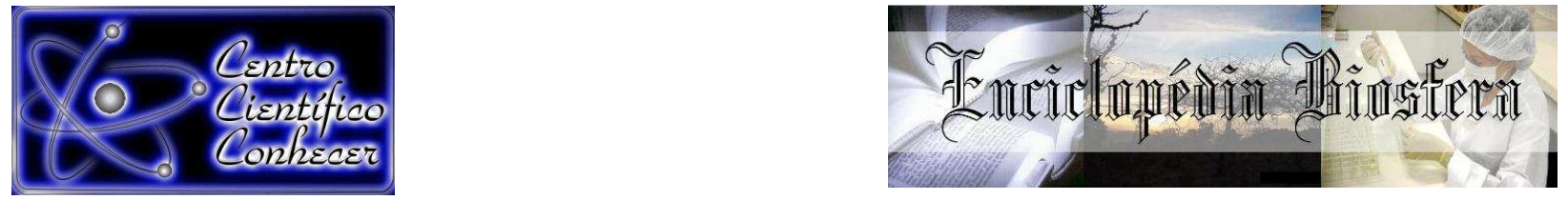

\title{
GERENCIAMENTO DE RESIDUOS SÓLIDOS RECICLÁVEIS E A LOGÍSTICA REVERSA: UM ESTUDO DE CASO DE ASSOCIAÇÃO DE CATADORES
}

\author{
Wanderlei de Souza ${ }^{1}$, Cleiltan Novais da Silva ${ }^{1}$, Edneia S. Paccola ${ }^{1,2}$, José \\ Eduardo Gonçalves ${ }^{1,2}$ \\ ${ }^{1}$ Programa de Pós-graduação em Tecnologias Limpas, Centro Universitário de Maringá - \\ UniCesumar, Avenida Guedner, 1610, 87050-390, Maringá-PR. \\ ${ }^{2}$ Instituto Cesumar de Ciência, Tecnologia e Inovação - ICETI, Avenida Guedner, 1610, \\ 87050-900, Maringá-PR. (jose.goncalves@unicesumar.edu.br) \\ Recebido em: 02/10/2017 - Aprovado em: 21/11/2017 - Publicado em: 05/12/2017 \\ DOI: 10.18677/EnciBio_2017B116
}

\begin{abstract}
RESUMO
A sociedade, tem consciência da logística empresarial para atender suas necessidades de consumo. A Logística Reversa pode ser definida como uma área estratégica para desenvolvimento sustentável através do reaproveitamento ou retorno dos produtos, embalagens ou materiais do centro produtivo. O objetivo deste trabalho foi identificar os desafios relacionados como avanço da Logística Reversa no município de Mandaguari (PR) através do perfil dos colaboradores da Associação dos Catadores de Materiais Recicláveis de Mandaguari (ACAMAN), e analisar os principais problemas enfrentados, sugerindo medidas de prospecção que aprimorem a sustentabilidade eco-socioambiental. Portanto, foi realizada uma pesquisa qualitativa e exploratória, através de um estudo de caso na ACAMAN. O estudo envolveu pesquisa mediante entrevista e observação direta. Os resultados mostraram que a maioria dos funcionários eram do sexo feminino $(83,3 \%)$, com idades entre $26-35(37,5 \%)$ e tinham apenas o ensino fundamental incompleto $(66,6 \%)$. Na coleta seletiva, somente $5,2 \%$ dos bairros fez a separação adequada dos resíduos e o volume total de resíduos recicláveis coletados foi de 70 ton/mês. Constataram-se como principais problemas da ACAMAN, dificuldade de gestão organizacional relacionada a entrada de materiais e organização financeira, busca por técnicas que auxiliem o aumento da renda, além de formas eficientes de sensibilização ambiental da sociedade. A associação conta com ações de prospecção para a capacitação de gestores, parcerias que viabilizem investimentos em tecnologias de beneficiamento dos materiais, agregando valor ao produto. Além da divulgação do processo de coleta seletiva e sensibilização da população frente a importâncias dessas atividades para o desenvolvimento socioambiental do município.
\end{abstract}

PALAVRAS-CHAVE: Gestão de Resíduos de PET. Reutilização. Sustentabilidade.

\section{MANAGEMENT OF RECYCLABLE SOLID WASTE AND REVERSAL LOGISTICS: CASE STUDY OF ASSOCIATION OF GARBAGE COLLECTORS}

\footnotetext{
ABSTRACT

Society is generally aware of the importance of business logistics to meet its consumption needs. Reverse Logistics which can be defined as a practical and strategic area for development through the reuse or return of products, packaging or
} 
materials in its production center. The objective of the study was to evaluate the challenges related to the post-consumer Reverse Logistics in the municipality of Mandaguari (PR) and to identify the profile of the employees of the Association of Collectors of Recyclable Materials of Mandaguari (ACAMAN) analyzing the main problems faced by the organization, suggesting prospecting measures that improve eco - socio - environmental sustainability. Therefore, a qualitative and exploratory research was carried out, whose means of investigation used a case study at ACAMAN, the study involved field research through an interview with the association manager and direct observation. According to the result, the profile of the employees was drawn, most of whom were female (83.3\%), aged between 26 - 35 (37.5\%) and had only incomplete elementary education (66.6\%). Regarding the selective collection, only $5.2 \%$ of the districts do the proper separation of the residues and the total volume of recyclable waste collected was 70 tons / month. The main problems of ACAMAN were the difficulty of organizational management related to the entry of materials and financial organization, the search for techniques that help to increase income, as well as efficient forms of environmental awareness of society. The organization also has prospecting actions to train managers, establishing partnerships that enable investments in materials processing technologies, adding value to the product. Disseminating the process of selective collection and sensitization of the population regarding the importance of these activities for the socio-environmental development of the municipality.

KEYWORDS: Waste Management. Reuse. Sustainability.

\section{INTRODUÇÃO}

O crescimento populacional associado a intensa urbanização e a crescente utilização de materiais não recicláveis no processo produtivo, ligados aos padrões atuais de consumo constantes e o lançamento de novas tecnologias que tornam os produtos rapidamente obsoletos, tem transformado a questão resíduos tanto urbanos como rurais em um dos grandes desafios ambientais contemporâneo (GOUVEIA, 2012; VIRGOLIN et al., 2016).

No entanto, pesquisas apontam que a preocupação mundial em relação aos resíduos sólidos, em especial os domiciliares, tem aumentado diante do crescimento da produção, da gestão inadequada e da falta de áreas de disposição final (SILVAJUNIOR et al., 2016). Visto que, a gestão e disposição inadequada desses resíduos podem gerar impactos socioambientais, tais como degradação do solo, contaminação dos corpos de água, aumento da proliferação de vetores de importância sanitária, além de comprometerem a drenagem urbana contribuindo para alagamentos e enchentes, sendo que estes fatores apresentam consequências direta ou indireta para a saúde pública e ambiental (JACOBI; BESEN, 2011; SILVAJUNIOR et al., 2016; PINHEIRO et al., 2016).

Os problemas referentes a destinação final dos resíduos sólidos urbanos têm se transformado em um dos maiores desafios da gestão pública no Brasil (RIBEIRO, 2014), pois, tal fato acarreta um aumento dos custos relacionados com o tratamento ou pela limitação da capacidade dos aterros sanitários. Jacobi (2006) ressalta que esses resíduos são destinados aos aterros sanitários de maneira paliativa ou em grande parte são descartados em locais inadequados (aterros controlados/lixões).

Desta forma, a reciclagem e o reuso dos resíduos sólidos consistem em uma ferramenta de gestão recomendada pela Política Nacional de Resíduos Sólidos (PNRS), implementada pela Lei 12.305 (BRASIL, 2010), a qual define as melhores 
formas de destinação final dos resíduos e também maneiras de incrementar valor financeiro a estes, priorizando a não geração, redução, reutilização, reciclagem, tratamento dos resíduos sólidos e disposição final ambientalmente adequada dos rejeitos. A PNRS também incentiva a adoção de práticas de logística reversa e coleta seletiva a fim de impedir a mistura dos resíduos e a contaminação destes, mesmo sabendo que este processo de coleta seletiva e logística reversa pode encarecer ou dificultar o processo de reuso e reciclagem (BAEDER; PONTUSCHKA, 2011).

A coleta seletiva é um importante mecanismo para desviar do aterro sanitário os resíduos sólidos que poderiam ser reciclados, aumentando a vida útil do aterro e evitando a degradação do meio ambiente (GONÇALVES, 2006). O potencial de reaproveitamento e reciclagem de matérias-primas obtidas através da coleta seletiva, pode proporcionar uma redução da demanda de recursos naturais, além de constituir como fonte de renda e também como inclusão social para muitos trabalhadores (JACOBI, 2006).

Outro ponto importante na referida lei é a inclusão social dos catadores de materiais recicláveis, sendo que estes desempenham papel fundamental na implementação da PNRS, atuando nos processos que vão desde a coleta seletiva até a comercialização dos resíduos recicláveis, contribuindo de forma significativa para a cadeia produtiva da reciclagem (BRASIL, 2010). Diante de tal importância, a PNRS incentiva a criação de cooperativas ou associação de catadores de materiais recicláveis e define como prioridade a sua participação nos sistemas de coleta seletiva e de logística reversa.

Logo, a consolidação da organização produtiva dos catadores, em cooperativas e associações com base nos princípios da autogestão, da economia solidária e do acesso a oportunidades de trabalho representa, portanto, um avanço na ampliação da área de atuação desta categoria profissional na implementação da PNRS, em especial na cadeia produtiva da reciclagem, traduzindo-se em oportunidades de geração de renda e de negócios, fortalecendo a comercialização em rede, a prestação de serviços, a logística reversa e na adoção da estratégia da verticalização da produção (BRASIL, 2010).

Diante do contexto, o objetivo do trabalho foi identificar os desafios relacionados com o avanço da Logística Reversa de pós-consumo no município de Mandaguari (PR) através do perfil dos colaboradores da Associação dos Catadores de Materiais Recicláveis de Mandaguari (ACAMAN), bem como os principais problemas enfrentados pela organização, sugerindo medidas de prospecção que aprimorem a sustentabilidade eco-socioambiental.

\section{MATERIAL E MÉTODOS}

Para esse estudo, foi realizada uma pesquisa qualitativa, exploratória, cujos meios de investigação foram a revisão bibliográfica através de uma abordagem teórica do problema, caracterizado pela pesquisa bibliográfica sobre o tema em livros, artigos científicos, revistas e periódicos em bases de dados eletrônicos (Scielo, Science Direct, Web of Science, Bireme, LILACS e portal de periódicos da Capes) e um estudo de caso na Associação dos Catadores de Materiais Recicláveis de Mandaguari (ACAMAN). O estudo de caso envolveu pesquisa de campo por meio da investigação documental, entrevistas com os gestores da associação e observação direta realizada durante as visitas às instalações da ACAMAN. 


\section{Caracterização da área de trabalho}

O local escolhido para o estudo de caso foi a Associação dos Catadores de Materiais Recicláveis de Mandaguari (ACAMAN). A ACAMAN foi fundada no ano de 2007, com sede no município de Mandaguari estado do Paraná, localizado entre as coordenadas $23^{\circ} 32^{\prime} 52^{\prime \prime}$ latitude Sul e $51^{\circ} 40^{\prime} 15^{\prime \prime}$ longitude Oeste. O município de Mandaguari tem área territorial de $335,814 \mathrm{~km}^{2}(2016)$ e densidade demográfica de $97,25 \mathrm{hab} / \mathrm{km}^{2}$ (2010), com uma população estimada para o ano de 2017 de 34.559 habitantes e no último senso em 2010 de 32.658 habitantes residentes no município, segundo dados do IBGE (2010).

\section{Coleta de dados}

Com base na pesquisa bibliográfica, foi possível elaborar um roteiro descritivo para a entrevista. A entrevista foi conduzida pelo pesquisador do trabalho, e realizada com o gestor (diretor) além da participação do tesoureiro da organização da ACAMAN e nesta entrevista foi abordada questões relacionadas à coleta seletiva, tipo e volume de materiais separados/reciclados, preço e canais de venda, além de questões relacionadas à contratação e perfil dos funcionários, buscando analisar a inserção social do setor.

A análise documental foi realizada na sede da ACAMAN sob supervisão do tesoureiro da associação no período de março a junho de 2017. Foram analisados os documentos da ACAMAN referentes ao período de janeiro de 2016 até junho de 2017.

\section{Análise de dados}

Os dados coletados na entrevista e também as informações extraídas da análise documental foram organizados, tabulados e analisados em planilha eletrônica por meio do programa Excel 2016. Os resultados configurados em forma de Tabelas. O Quadro 1 apresenta os temas abordados durante a entrevista, que corresponde questões do tipo aberta, para permitir respostas livres e com uso de linguagens próprias.

QUADRO 1: Formulário de entrevista realizada na ACAMAN

\begin{tabular}{l|l}
\hline Tema & Desenvolvimento \\
\hline $\begin{array}{l}\text { Histórico de criação e } \\
\text { composição } \\
\text { associação. }\end{array} \quad \begin{array}{l}\text { Comente em relação à criação da associação, início das } \\
\text { atividades, das motivações iniciais, da criação de seu estatuto, } \\
\text { da composição inicial dos funcionários. }\end{array}$ \\
\hline $\begin{array}{l}\text { Operacionalização da } \\
\text { associação. }\end{array}$ & $\begin{array}{l}\text { Relate quais são as atividades da associação, os procedimentos } \\
\text { operacionais utilizados, os principais resultados, a capacidade } \\
\text { de produção e os equipamentos utilizados. }\end{array}$ \\
\hline $\begin{array}{l}\text { Remuneração } \\
\text { Capacitação }\end{array}$ & $\begin{array}{l}\text { Foi questionado a associação qual o valor médio arrecadado } \\
\text { mensal, qual a renda mensal média dos funcionários e qual a } \\
\text { política de capacitação das entidades. }\end{array}$ \\
\hline $\begin{array}{l}\text { Parcerias com o poder } \\
\text { público e entidades } \\
\text { privadas. }\end{array}$ & $\begin{array}{l}\text { Questionou-se como se dá à parceria da associação com a } \\
\text { prefeitura e outras entidades públicas e privadas, quais os } \\
\text { benefícios concedidos para associação pelo poder público, bem } \\
\text { como quais benefícios que poderiam ser concedidos pelo poder } \\
\text { público municipal visando ajudar à associação. }\end{array}$ \\
\hline $\begin{array}{l}\text { Dificuldades e objetivos } \\
\text { futuros }\end{array}$ & $\begin{array}{l}\text { Quais as dificuldades encontradas pela associação e o que falta } \\
\text { para ambas serem consideradas uma alternativa mais eficiente } \\
\text { de geração de emprego e renda. }\end{array}$ \\
\hline
\end{tabular}

Fonte: Elaborado pelos Autores. 


\section{RESULTADOS E DISCUSSÃO}

A ACAMAN, objeto deste estudo, está vinculada à Secretaria do Meio Ambiente do município de Mandaguari - PR. A associação é composta por 24 funcionários. A contratação de novos prestadores (funcionários) pela ACAMAN não leva em consideração o grau de escolaridade e nem a experiência profissional, sendo este um fator muito importante de inclusão social de uma classe da população menos favorecida.

Através da análise documental da ACAMAN, observou-se que a maioria dos prestadores tinha entre 26 a 35 anos, seguido pela faixa etária entre 18 a 25 anos e daqueles com mais de 46 anos, como mostra a Tabela 1. Em relação ao gênero, verificou-se que a maioria absoluta, 20 funcionários pertenciam ao sexo feminino e 4 (quatro) do sexo masculino. Na distribuição de função dentro da ACAMAN 3 (três) funcionários do sexo masculino ocupavam o cargo de motorista e 01 (um) de auxiliar de motorista, já as funcionárias, uma ocupava o cargo de gestora da associação, uma o cargo de finanças da ACAMAN e as demais, 18, organizadas na função de catadoras e triagem e acondicionamento dos resíduos (Tabela 1).

O perfil da população amostrada também corresponde ao encontrado nos estudos realizados por Almeida et al. (2009) e Arantes e Borges (2013), em que a maioria dos trabalhadores são mulheres e possuem baixa escolaridade. Arantes e Borges (2013) reforçam que na atividade de catadores, predominaram mulheres, casadas ou com outras formas de união, pardos e negros, com instrução formal limitada e baixo rendimento. Os autores apontam que o perfil traçado pelas características da sociedade brasileira, retrata as exclusões de gênero, cor, educação e pouca oportunidade, demandando intervenções sociais para seu rompimento.

TABELA 1- Perfil dos funcionários da Associação dos Catadores de Materiais Recicláveis de Mandaguari - ACAMAN

\begin{tabular}{|c|c|c|}
\hline Idade & Frequência & Percentual (\%) \\
\hline De 18 a 25 anos & 6 & 25,0 \\
\hline De 26 a 35 anos & 9 & 37,5 \\
\hline De 36 a 45 anos & 3 & 12,5 \\
\hline Acima de 46 anos & 6 & 25,0 \\
\hline Total & 24 & 100 \\
\hline Gênero & Frequência & Percentual (\%) \\
\hline Feminino & 20 & 83,3 \\
\hline Masculino & 4 & 16,7 \\
\hline Total & 24 & 100 \\
\hline Escolaridade & Frequência & Percentual (\%) \\
\hline Sem escolaridade & 2 & 8,3 \\
\hline Ensino Fundamental I Incompleto ( $1^{\frac{a}{a}}$ a $\left.5^{a}\right)$ & 16 & 66,7 \\
\hline Ensino Fundamental I Completo & 4 & 16,6 \\
\hline Ensino Fundamental II Incompleto (6 $6^{\mathrm{a}}$ a $9^{\mathrm{a}}$ ) & 1 & 4,2 \\
\hline Ensino Fundamental II Completo & 0 & 0,0 \\
\hline Ensino Médio Completo & 0 & 0,0 \\
\hline Ensino Médio Incompleto & 0 & 0,0 \\
\hline Ensino Superior Incompleto & 0 & 0,0 \\
\hline Ensino Superior Completo & 1 & 4,2 \\
\hline Total & 24 & 100 \\
\hline
\end{tabular}


Com uma dispersão maior, a escolaridade dos funcionários variou desde a categoria sem escolaridade até o nível superior completo. Em que a maioria declarou que cursou o ensino fundamental I incompleto, seguido do ensino fundamental completo, sem escolaridade, apenas um funcionário tem o ensino superior completo e ocupa o cargo de gestor da associação (Tabela 1). Assim, através dos dados destacamos um baixo nível de escolaridade dos prestadores de serviço da ACAMAN, onde 23 funcionários $(95,8 \%)$ apresentam escolaridade igual ou inferior ao ensino fundamental I incompleto. A funcionária que apresenta formação superior é responsável pela gestão financeira da ACAMAN.

No estudo realizado por Poças et al., (2010) avaliando o perfil de colaboradores de uma Associação de Materiais Recicláveis de Vitória - ES, mostraram que os catadores apresentaram um perfil de baixa escolaridade e relataram que a sua permanência nesta atividade seria devida as dificuldades de inserção no mercado de trabalho. Esses resultados corroboram com a afirmação de Aquino et al. (2009) relatam que as cooperativas melhoram a situação de comunidades mais vulneráveis, pois oferecem a seus membros opção de emprego e renda. Este fato pode ser confirmado neste estudo, uma vez que aproximadamente $95,8 \%$ dos colaboradores da associação não têm o ensino médio completo, ou seja, as associações de catadores constituem uma das formas mais importantes inserção das classes com menor grau de escolaridade no mercado.

Os catadores de resíduos sólidos e as associações de materiais recicláveis desempenham papel fundamental para a implementação das PNRS (Política Nacional de Resíduos Sólidos), contribuindo diretamente com a gestão integrada dos resíduos sólidos, cuja atividade profissional é reconhecida pelo Ministério do Trabalho e Emprego desde 2002 (BRASIL, 2002). Os catadores de resíduos sólidos representam uma classe de agentes essenciais na prestação de serviço ambiental, visto que atuam reduzindo os resíduos e consequentemente o impacto causado pelos mesmos em áreas urbanas (Gonçalves et al., 2013). As cooperativas de reciclagem são elementos atuantes em cadeias reversas de recuperação de valor de resíduos que recebem e segregam os materiais com valor agregado (CRUVINEL et al., 2015).

As associações ou cooperativas de catadores e recicladoras contribuem para a redução do descarte inadequado de resíduos, para o aumento da vida útil dos aterros sanitário, diminui a demanda de recursos naturais e contribui com a reinserção desses materiais nas indústrias recicladoras que posteriormente irão abastecer a cadeia produtiva, substituindo o uso de matérias primas virgem (AQUINO et al., 2009; RIBEIRO, et al., 2014; ALMEIDA et al., 2014). Gouveia (2012) completa que, a reutilização de resíduos sólidos como matéria prima, beneficia diretamente a redução da poluição ambiental e indiretamente a diminuição do uso de energia, e ambas situações reduzem as emissões de gases que causam o aquecimento global, além de também consolidam os programas da cadeia da logística reversa através do fornecimento de matéria-prima para a indústria (SOUZA et al., 2012).

A PNRS também reconhece que os resíduos sólidos recicláveis são um bem econômico e de valor social, gerador de trabalho e renda, promovendo a cidadania e a responsabilidade compartilhada. Também define que a participação no sistema de coleta seletiva e logística reversa deve ser priorizada para o saneamento básico. Nessa mesma linha o governo federal visa dar a oportunidade de inclusão socioeconômica dos catadores (BRASIL, 2010). 
Com relação a estrutura física, a ACAMAN funciona em um galpão de triagem com $700 \mathrm{~m}^{2}$ e conta com duas mesas de triagem, uma balança digital de piso Toledo 2198C com capacidade para uma tonelada, 40 bags e uma prensa. Além disso, o contrato de prestação de serviços com a prefeitura do município de Mandaguari-PR permitiu a contratação de três caminhões com motoristas, em que um faz a coleta dos grandes geradores que compreende uma indústria e uma cooperativa, e os outros dois realizam a coleta seletiva nos bairros do município. Segundo os gestores da associação, tanto a mão de obra quanto a disponibilidade de maquinaria são suficientes para atender a demanda do município. Atualmente, a associação funciona também como Ponto de Entrega Voluntária (PEV) de resíduos volumosos, como sofás e armários, em que todos os materiais são recebidos e destinados de forma ambientalmente adequada.

A coleta seletiva realizada pela ACAMAN atende todos os bairros do município, porém do total de 38 bairros existentes no município de Mandaguari-PR, apenas dois, totalizando $5,3 \%$ dos bairros realizam a separação dos resíduos recicláveis de forma satisfatória utilizando sacos verdes, cor padrão para materiais recicláveis como determina a Secretaria do Meio Ambiente do Município de Mandaguari-PR. No entanto, os demais bairros não fazem a separação correta, misturam materiais orgânicos com recicláveis, dificultando o processo de reciclagem. Segundo Soares et al. (2007), uma etapa necessária para a reciclagem de resíduos sólidos é a coleta seletiva, sendo esta uma alternativa ecologicamente correta para a preservação do meio ambiente e melhoria da qualidade de vida da população. Besen et al. (2014), reforçam que, a coleta seletiva de resíduos recicláveis e a reciclagem são ações que contribuem para a sustentabilidade urbana que refletem na saúde ambiental e humana.

Porém, quando abordado sobre a sensibilização ambiental da população do município, frente ao processo de separação dos resíduos para coleta, os membros da associação relataram que o sistema de coleta não está claro para a maior parte dos habitantes do município, pois foram realizadas apenas entrevistas no rádio local, faltando empenho do poder público, para aumentar a divulgação para toda a comunidade. Cabe ressaltar que, primeiramente para a implantação de um sistema de coleta seletiva faz-se necessário a realização de campanhas junto à população, mostrando a relevância do processo de reciclagem e orientando-a para a importância da separação do lixo em sua origem (SILVA et al., 2012).

Com relação ao volume de recicláveis coletado no Município, a associação mencionou que a quantidade gira em torno de 70 toneladas $/$ mês, sendo que 50 toneladas foram provenientes da rota de coleta residencial do município e 20 toneladas advindas de uma empresa privadas e uma cooperativa (Tabela 2).

TABELA 2. Volume mensal e tipo de resíduos coletados pela ACAMAN no município de Mandaguari

\begin{tabular}{lccc}
\hline \multirow{2}{*}{$\begin{array}{l}\text { Tipo de } \\
\text { material }\end{array}$} & \multicolumn{2}{c}{ Volume/ton. } & Volume/total \\
\cline { 2 - 3 } & Residencial & Empresarial & \\
\hline $\begin{array}{l}\text { Polietileno, } \\
\text { papelão, } \\
\text { garrafas PET, } \\
\text { alumínio. }\end{array}$ & 50 & 20 & 70 \\
\hline
\end{tabular}


Nesse cenário, torna-se importante a formação de parceiros comerciais como as escolas, catadores, sucateiros, indústrias, para melhorar o sistema de coleta e separação dos resíduos recicláveis. A lei da Política Nacional de Resíduos Sólidos (PNRS) de 2010 reforça a importância das parcerias envolvendo os fabricantes e distribuidores na implementação da responsabilidade compartilhada, já que estes têm a responsabilidade com a destinação final correta de tudo àquilo que produzem (BRASIL, 2010).

Os dados levantados neste estudo permitiram a elaboração de um fluxograma simplificado das principais etapas de funcionamento da ACAMAN, iniciando pela coleta seletiva de materiais recicláveis e finalizando com a comercialização (Figura 1).

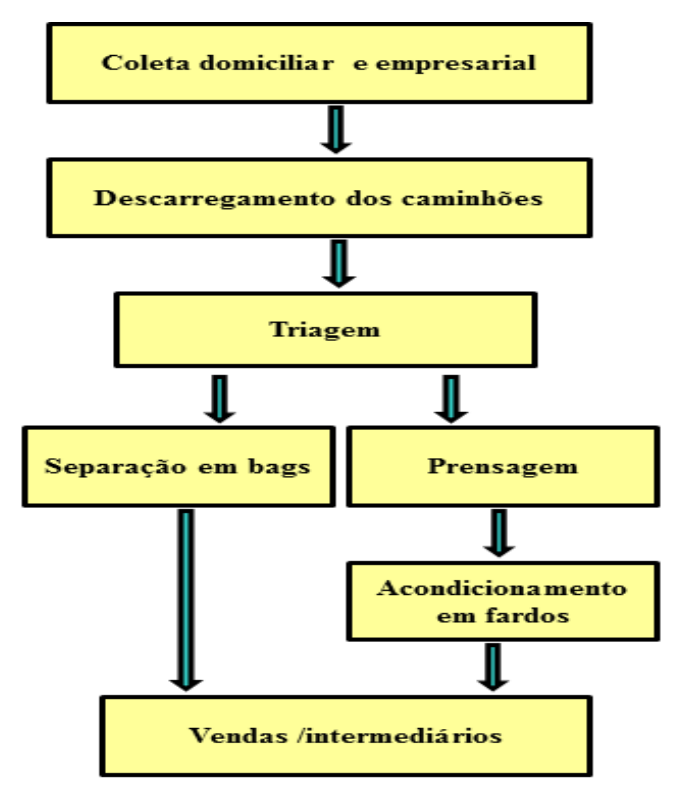

FIGURA 1- Fluxograma da cadeia produtiva de materiais envolvendo associação de catadores de recicláveis de Mandaguari (ACAMAM)

Após passar por todas as etapas que iniciou na coleta, observou-se que a ACAMAM comercializa seu produto com um único comprador, conhecido dentro desse sistema como intermediário, que repassa para as indústrias de reciclagem. Dentro da área de abrangência nesse estudo, foi verificado que há pouco ou nenhum conhecimento sobre as recicladoras, ou seja, são desconhecidos os atores do nível seguinte da cadeia produtiva reversa.

Como mencionado anteriormente, à venda dos materiais é realizada diretamente pela associação para um comprador, morador de outro município, que leva tudo o que é recolhido/produzido. Através da análise dos documentos da ACAMAN realizada no período de janeiro de 2016 até junho de 2017, o rendimento obtido pela venda dos resíduos sólidos reciclados fica em torno de $R \$$ $24.485,00$ /mês (Tabela 3 ). Além deste recurso oriundo da venda dos resíduos, a associação recebe uma contrapartida do Governo Federal, por intermédio da prefeitura municipal de Mandaguari-PR no valor de $R \$ 34.567,00 /$ mês para custear suas despesas. Dessa forma, somando o valor do convênio através da prefeitura municipal e o valor com o faturamento arrecadado pela venda dos resíduos sólidos 
recicláveis, gera um faturamento mensal pela ACAMAM de $R \$ 59.052,00 /$ mês. Segundo os gestores da ACAMAN, relacionando o custo fixo em torno de R $\$$ $50.000,00$ e a seu faturamento de 59.052,00, a mesma comprova sua viabilidade, uma vez que apresentou a rentabilidade de $15,3 \%$ e o índice de lucratividade de $1,18 \%$.

TABELA 3. Materiais coletados, volume e valor de venda dos resíduos comercializados pela ACAMAN.

\begin{tabular}{lccc}
\hline Tipo de material & Quantidade/ton. & $\begin{array}{c}\text { Preço } \\
\mathbf{R} \mathbf{k g}\end{array}$ & Total R\$ \\
\hline Polietileno cristal & 3.5 & 1,20 & $4.200,00$ \\
Polietileno colorido & 2.5 & 0,40 & $1.000,00$ \\
Papel/papelão & 36.0 & 0,40 & $14.400,00$ \\
Garrafas PET & 2.0 & 1,10 & $2.200,00$ \\
Alumínio & 0,50 & 3,50 & $1.750,00$ \\
Outros & 8.5 & 0,11 & 935,00 \\
\hline Total & 53.0 & & $24.485,00$ \\
\hline
\end{tabular}

Considerando que $58,5 \%$ do faturamento da ACAMAN vem do poder público através da prefeitura do município de Mandaguari-PR e este valor é utilizado para pagamentos de salários dos funcionários e as despesas fixas da estrutura física da ACAMAN, o índice de lucratividade, assim como a rentabilidade tornam-se positivos em função deste aporte financeiro.

Gouveia (2012) menciona que para melhorar os índices de lucratividade, são necessárias ações que incentivem a coleta seletiva, bem como a segregação adequada das diferentes matérias, tanto pela população no momento da geração de resíduos como nos centros de triagem.

A Tabela 3 mostra que o maior volume de resíduo da ACAMAN e o maior valor arrecadado é o papel/papel, mas o valor agregado por quilo é baixo. Já os resíduos de plásticos que incluem o polietileno e o PET apresentam valores agregado na vendo por quilo maior. Podemos destacar que as garrafas PET têm um grande potencial para comercialização, uma vez que o PET reciclado pode ser utilizados em diversos produtos, inclusive em produtos de alto valor agregado, tais como peças plásticas para utilização automobilística. Outro fator importante é o grande consumo de produtos que utilizam materiais de PET, assim através de uma orientação adequada da população este volume coletado poderá aumenta significativamente.

Com base no que foi levantado nas entrevistas e observados pelos pesquisadores durante as visitas in loco a ACAMAM, tanto em relação à aspectos socioeconômicos dos colaboradores, como referentes a gestão e estrutura física disponível, foram elaboradas algumas proposições de ações para a associação estudada, no sentido de contribuir para a melhoria do processo de reciclagem, da logística reversa e da agregação de valor aos materiais comercializados.

A partir das visitas realizadas nos galpões através organização do processo produtivo, observou-se o acúmulo dos materiais recicláveis coletados, o que dificulta a movimentação de materiais e pessoas, causando desconforto no ambiente de trabalho. Dessa forma, propõem-se a organização do processo produtivo que leve em conta as seguintes características: 1) Os matérias coletados devem ser 
colocados em áreas demarcadas dentro do galpão com tinta de diferentes cores, obedecendo a uma sequência lógica do processo produtivo dos materiais coletados; 2) Deve levar em conta o tipo de material reciclado; 3) volume dos resíduos sólidos.

Segundo Oliveira Neto et al. (2015), a organização dos recursos de produção tem papel fundamental no processo de uma empresa, pois, se bem montado, permitirá a via mais adequada da primeira à última operação, reduzindo a circulação de mercadorias, ou seja, a movimentação desnecessária produto. Esta organização ajuda também na identificação do tipo de material reciclado e sua qualidade.

Quanto à gestão organizacional da associação, nesse estudo, foram encontradas dificuldades em levantar informações sobre alguns aspetos como, a quantidade de cada tipo de material coletado (vidro, alumínio, papel, plástico), além de informações sobre a prestação de contas. A ACAMAM possui apenas um gestor, dessa forma, propõe-se que o mesmo, seja capacitado, através curso de informática, com ênfase no programa de elaboração de planilhas eletrônicas e seja instruído a elaborar banco de dados para o controle efetivo do material coletado e das finanças, organizando todas as informações referentes às atividades da associação.

Em relação ao aumento da renda, um dos maiores problemas identificados foi referente à comercialização dos materiais. Este fato está diretamente relacionado com a falta de equipamentos necessários para avançar no processo de reciclagem e consequentemente na agregação do valor aos recicláveis. Por exemplo, a garrafas PET poderiam ser moídas (flake), resultando em flocos ganhando valor no mercado (BELTRÃO, 2007; COELHO et al., 2016). No entanto, há possibilidade de valorizar ainda mais o produto, produzindo os pellets, produto mais condensado, otimizando o transporte e o desempenho na transformação (COELHO et al., 2016), porém devido a falta de equipamento, essa etapa não é realizada pela associação. Dessa maneira, a alternativa encontrada pelos gestores foi vender os recicláveis para os intermediários, os quais compram os materiais por um valor inferior quando comparado com as vendas diretas para as indústrias de reciclagem.

Algumas ações foram propostas visando melhoria na renda dos catadores ligados a ACAMAN, através da busca de parcerias com instituições públicas/privadas com interesse em investir em tecnologias de beneficiamento dos materiais recicláveis e no aumento da quantidade de materiais coletados e destinados a reciclagem, sendo para este caso fundamental um trabalho de divulgação nos meios de comunicação de massa como TV e rádios ou ainda em reuniões nas associações dos bairros ou igrejas dos benefícios ambientais da separação dos resíduos e a importância da coleta seletiva.

Ressalta-se, que a sensibilização ambiental da sociedade se caracteriza como um dos aspectos fundamentais para o sucesso da cadeia produtiva da reciclagem, principalmente no que refere as questões citadas anteriormente como, o aumento de renda e da quantidade de materiais coletados e destinados à reciclagem. Como observado neste estudo, apenas uma minoria dos bairros faz a separação de resíduos de forma satisfatória, ou seja, a população precisa ser sensibilizada para compreender a importância da separação dos materiais recicláveis, e isso acontecerá mediante a inserção de projetos de educação ambiental. De acordo com D`Almeida e Vilhena (2000) o sucesso para a coleta seletiva está diretamente ligado aos investimentos feitos para sensibilização e conscientização da população. 
Dessa forma, para que um programa de educação ambiental aconteça de forma eficiente é necessário que o maior número de segmentos da sociedade participe. Assim, propõe-se que tanto poder público, como as instituições privadas, bem como associações, cooperativas e sociedade em geral promovam ações que remetam a educação ambiental em escolas e meios de comunicação, destacando que a preservação ambiental é responsabilidade de todos.

Um dos maiores entraves para a associação de catadores avançarem na cadeia reversa de pós-consumo está relacionada com as exigências das indústrias recicladoras, pois, estas geralmente exigem quantidades mínimas de carga para os diferentes tipos de materiais e frequência mínima de entrega. A ACAMAN trabalha com pouco volume de materiais quando comparado com as exigências da indústria recicladoras, desse modo como alternativa vende os materiais com preço inferior para pessoas conhecidas como intermediário.

Diante disso, propõe-se que as associações de catadores da região de Mandaguari trabalhem conjuntamente, com a finalidade de disponibilizar um maior volume de materiais para a indústria recicladora e praticando a venda direta, agregando valor ao produto. Conforme discutido por Aquino et al. (2009) a alternativa de articulação em redes ou federações das associações, favorecem os aspectos social e econômico por meio da agregação de valor aos materiais recicláveis recolhidos pelos catadores. Segundo estudos realizados pelo mesmo autor se as associações se organizassem em redes, todas conseguiriam comercializar produtos diretamente com indústrias recicladoras, e agregariam $32 \%$ no valor dos produtos comercializados.

$\mathrm{Na}$ relação da logística reversa Souza et al. (2012) destaca que as cooperativas contribuem com o prolongamento da vida útil de produtos e embalagens por meio da coleta, separação e fornecimento de matéria-prima secundária para a indústria, consolidando assim programas de logística reversa que buscam a recuperação de produtos recicláveis. Ressaltando que, a principal questão da logística reversa é a forma com a qual se planeja e implementa um controle de resíduos de pós-consumo e pós-venda e desenvolve todo um fluxo de materiais do ponto de consumo até o ponto de origem, com o intuído de reaproveitar a matéria ou fazer o descarte com o menor impacto ambiental possível (CASIMIRO et al., 2014).

Assim, almeja-se que a implementação das propostas apresentadas, contribua de forma positiva em todo processo produtivo de recicláveis, bem como na gestão dos resíduos sólidos, e na geração de renda para Associação dos Catadores de Materiais Recicláveis de Mandaguari (ACAMAN), culminando com a melhoria da qualidade de vida de todos envolvidos neste processo e que a implantação destas propostas sirva de modelo para as pequenas associações e organizações de catadores de matérias recicláveis espalhadas em todo Brasil.

\section{CONCLUSÃO}

A análise do perfil dos funcionários da Associação dos Catadores de Materiais Recicláveis de Mandaguari - ACAMAN mostrou que a maioria dos colaboradores apresentaram um grau de escolaridade muito baixo e que pessoas do sexo feminino eram predominantes. Foram identificados os problemas enfrentados pela associação, dentre os quais destacaram a dificuldade de gestão organizacional relacionada principalmente com a entrada materiais e questões financeiras, a busca por técnicas que auxiliem o aumento da renda, além de formas eficientes de sensibilização ambiental da sociedade. Diante dessas problemáticas, foram elaboradas propostas de melhorias para ACAMAM como, a organização do espaço 
direcionado para o processo produtivo, o estabelecimento de parcerias com a finalidade de aquisição de investimento em tecnologias de beneficiamento dos materiais, projetos de divulgação de coleta seletiva e sensibilização da população frente a importâncias dessas atividades para o desenvolvimento socioambiental do município. A valorização do serviço de coleta seletiva aliado a demanda crescente na produção de resíduos recicláveis, bem como o aumento do valor agregado ao produto através da logística reversa representam propostas trabalhos futuros.

\section{REFERÊNCIAS}

ALMEIDA, J. R, ELIAS, E. T., MAGALHÃES, M. A. \& VIEIRA, A. J. D. Efeito da idade sobre a qualidade de vida e saúde dos catadores de materiais recicláveis de uma associação em Governador Valadares, Minas Gerais, Brasil. Ciência e Saúde Coletiva, v. 14, n. 6, p. 2169-2179, 2009. Disponível em: < http://www.scielo.br/scielo.php?script=sci_arttext\&pid=S1413-

$81232009000600024 \&$ Ing=en>. Doi: $10.1 \overline{5} 90 /$ S1413-81232009000600024.

ALMEIDA, F. A.; VIANA, A. P. S.; RITTER, Á. M.; SELLITTO, M. A. Cooperativas de catadores de resíduos e cadeias logísticas reversas: estudo de dois casos. Revista Eletrônica em Gestão, Educação e Tecnologia Ambiental, v. 17, n. 17, p. 33763387, $2014 . \quad$ Disponível em:< https://periodicos.ufsm.br/index.php/reget/article/view/10911>. Doi: $10.5902 / 2236117010911$

AQUINO, I.; CASTILHO JR., A.; PIRES, T. A organização em rede dos catadores de materiais recicláveis na cadeia produtiva reversa de pós-consumo da região da grande Florianópolis: uma alternativa de agregação de valor. Gestão \& Produção, v. 16, n. 1, 2009. Disponível em:< http://www.scielo.br/pdf/gp/v16n1/v16n1a03>.Doi: $10.1590 /$ S0104-530X2009000100003

ARANTES, B. O.; BORGES, L. O. Catadores de materiais recicláveis: cadeia produtiva e precariedade. Arquivos Brasileiros de Psicologia, v. 65, n. 3, p. 319337, 2013.2 Disponível em: <http://pepsic.bvsalud.org/scielo.php?script=sci_arttext\&pid=S1809-

$52672013000300002 \&$ lng $=$ pt\&nrm=iso $>$.

BAEDER, A. M., \& PONTUSCHKA, N. N. A coleta seletiva em um projeto de pesquisa participativa. Revista Geográfica de América Central, 2 (47E), 2011. Disponível

em:

<http://www.revistas.una.ac.cr/index.php/geografica/article/view/2188>.

BELTRÃO, K. R. A. Reciclagem de PET. Dossiê técnico. Centro de Apoio ao Desenvolvimento Tecnológico da Universidade de Brasília - CDT/UnB. p.1-24, 2007.

BESEN, G. R.; RIBEIRO, H. G.; WANDA M. R.; JACOBI, P. R. Coleta seletiva na Região Metropolitana de São Paulo: impactos da Política Nacional de Resíduos Sólidos. Ambiente \& Sociedade, v. 17, n. 3, p. 259-278, 2014. Disponível em: $<$ http://www.scielo.br/scielo.php?script=sci_arttext\&pid=S1414-

753X2014000300015\&lng=en\&nrm=iso >. Doi: 10.1590/S1414-753X2014000300015 
BRASIL. Lei no 12.305, de 2 de agosto de 2010. Institui a Política Nacional de Resíduos Sólidos (PNRS); altera a Lei no 9.605, de 12 de fevereiro de 1998; e dá outras providências. Diário Oficial da República Federativa do Brasil, Poder Executivo, Brasília, DF, 03 mar. 2010. Disponível em:< http://www.mma.gov.br/port/conama/legiabre.cfm?codlegi=636>

BRASIL, Ministério do Trabalho e Emprego, CBO - Classificação Brasileira de Ocupação - Portaria no 397, de 09 de outubro de 2002. Diário Oficial da República Federativa do Brasil. Disponível em: < http://www.mtecbo.gov.br/cbosite/pages/home.jsf>

CASIMIRO, R. L.; SILVA, R. S.; CINTRA-FILHO, W. A.; QUEMEL, R. Logística ambiental: estudo da disposição final adequada do resíduo do alho. RacFcatRevista de administração e contabilidade, n. 1, 2014. Disponível em: < http://revista.fcat.edu.br/index.php/racfcat/article/view/129>

COELHO, A. P. C.; PEIXOTO, C. L.; MURTA, A. L. S.; RODRIGUEZ, M. V. R.; JUNIOR, J. L. P. C. Logística Reversa De Garrafas Pet Para Construção De Casas Populares. Sustainable business International Jornal, p.1-23, 2016. Disponível em:<http://www.sbijournal.uff.br/index.php/sbijournal/article/view/116/116>

CRUVINEL, I. B.; PÁDUA, A. L; FERREIRA, E. M. Cooperativas de catadores de recicláveis. Enciclopédia Biosfera, v. 11 n. 21; p. 3068-3077, 2015. Disponível em:< http://www.conhecer.org.br/enciclop/2015b/multidisciplinar/Cooperativas.pdf>

D`ALMEIDA, M. L. O.; VILHENA, A. Lixo municipal: manual de gerenciamento integrado. 2. ed. São Paulo: IPT/CEMPRE, 2000. 370 p.

GONCALVES-DIAS, S. L. F.; TEODOSIO, A. S. S. Estrutura da cadeia reversa: "caminhos" e "descaminhos" da embalagem PET. Production, v. 16, n. 3, p. 429441,2006 . Disponível em: <http://www.scielo.br/scielo.php?pid=S010365132006000300006\&script=sci_abstract\&tlng=pt> Doi: 10.1590/S010365132006000300006 .

GOUVEIA, N. Resíduos sólidos urbanos: impactos socioambientais e perspectiva de manejo sustentável com inclusão social. Ciência \& saúde coletiva, v. 17, n. 6, p. 1503-1510, 2012. Disponível em:< http://www.scielo.br/scielo.php?pid=S141381232012000600014\&script=sci_abstract\&tlng=pt> Doi: 10.1590/S141381232012000600014 .

JACOBI, P. R.; BESEN, G. R. Gestão de resíduos sólidos em São Paulo: desafios da sustentabilidade. Estudos avançados, v. 25, n. 71, p. 135-158, 2011. Disponível em:< http://www.scielo.br/scielo.php?script=sci_arttext\&pid=S010340142011000100010>. Doi: 10.1590/S0103-40142011000100010

JACOBI, P. R.; VIVEIROS M. Da vanguarda à apatia, com muitas suspeitas no meio do caminho - gestão de resíduos sólidos domiciliares em São Paulo entre 1989 e 2004. In: JACOBI P. R. (Org.) Gestão compartilhada de resíduos sólidos no Brasil - inovação com inclusão social. São Paulo: Annablume, 2006, p. 65-86. 
OLIVEIRA NETO, G. C. FILHO, G.; VENDRAMETTO, M.; GANGA, O.; DEVÓS, G. M., \& Alencar, N., I.. Princípios e ferramentas da produção mais limpa: um estudo exploratório em empresas brasileiras. Revista Gestão e Produção, v. 22, n. 2, p. 326-344, 2015. Disponível em: <http://www.scielo.br/scielo.php?pid=S0104530X2015000200326\&script=sci_abstract\&tlng=pt>. DOI: 10.1590/0104-530X146814.

PINHEIRO, P. T.; FRANCISCHETTO, G. P. P. A política nacional de resíduos sólidos como mecanismo de fortalecimento das associações de catadores de materiais recicláveis. Derecho y Cambio Social. p. 1-24, 2016. Disponível em: <http://www.derechoycambiosocial.com/revista043/A_POLITICA_NACIONAL_DE_R ESIDUOS_SOLIDOS.pdf

POÇAS, J. F.; BORGES, M. R. C.; TORRES, S. M.; JÚNIOR, A. A. O. Os catadores de materiais recicláveis e a gestão pública de resíduos no município de Vitória-ES. Enciclopédia Biosfera, v.6, n.10, p. 1-15, 2010. Disponível em: <www.conhecer.org.br/enciclop/2010b/os\%20catadores.pdf >

RIBEIRO, L. C. S.; FREITAS, L. F. S.; CARVALHO, J. T. A.; OLIVEIRA FILHO, J. D. Aspectos econômicos e ambientais da reciclagem: um estudo exploratório nas cooperativas de catadores de material reciclável do Estado do Rio de Janeiro. Nova Economia, v. 24, n. 1, p. 191-214, 2014. Disponível em: <http://www.scielo.br/scielo.php?pid=S0103-

3512014000100191\&script=sci_arttext\&tlng=pt\#fn01 >. Doi:10.1590/103-6351/1390

SILVA-JUNIOR, F. L.; ALENCAR, M. N. A.; FEITOSA, A. K. A gestão de resíduos sólidos e a percepção interdisciplinar de órgãos gestores no município de Pio IX PI. Educação ambiental em ação, n. 58, 2016. Disponível em:< http://www.revistaea.org/artigo.php?idartigo=2560>.

SILVA, J.C.; OLIVEIRA, M. A.; PIRES, P. H.; SILVA, T. P.; RODRIGUES, M. Reciclagem energética: uma solução inovadora para o plástico não reciclável. Exacta, v. 4, n. 2, p. 87-96, 2011. Disponível em:< http://revistas.unibh.br/index.php/dcet/article/view/346> Doi: 10.18674/exacta.v4i2.346

SILVA, J. S.; OLIVEIRA, G.; RODRIGUES, A. P.; SILVA, H R G; AGRA, M D. Gerenciamento do lixo na cidade de esperança - PB: uma questão de educação ambiental. Anais do Encontro Nacional de Educação, Ciência e Tecnologia UEPB. 12, 13 e 14 de novembro de 2012. Disponível em:< http://www.editorarealize.com.br/revistas/enect/trabalhos/1556f2cc7819976919a5d2 2b348a121e_752.pdf>

SOARES, L G C; SALGUEIRO, A A; GAZINEU, M H P. Educação ambiental aplicada aos resíduos sólidos na cidade de Olinda, Pernambuco - um estudo de caso. Revista Ciências \& Tecnologia, n. 1, p. 1-9, 2007. Disponível em:< http://web-resol.org/textos/artigo5.pdf>

SOUZA, M. T. S..; PAULA, M. B. de.; SOUZA-PINTO, H. O papel das cooperativas de reciclagem nos canais reversos pós-consumo. RAE-Revista de Administração 
de Empresas, v. 52, n. 2, 2012. Disponível em: < http://rae.fgv.br/rae/vol52-num22012/papel-cooperativas-reciclagem-nos-canais-reversos-pos-consumo>. Doi: $10.1590 / \mathrm{S} 0034-75902012000200010$

VIRGOLIN, I. W. C; SILVA, E. M. T; SANTOS, R. R. Relato de experiencia sobre o projeto profissão catador: O lixo como fonte de trabalho e cidadania. Dialogo, n.3, p. 13-29, 2016. Doi: 10.18316/2238-9024.16.21 